\title{
A review of current work in research of Trombe walls
}

\author{
Xin Wang ${ }^{1}$, Qiao $\mathrm{Xi}^{1}$, and Qingsong $\mathrm{Ma}^{1, *}$ \\ ${ }^{1}$ Qingdao University of Technology, College of Architecture and Urban Planning, Shi Bei, Qingdao, Shandong, China
}

\begin{abstract}
Sustainable architecture and green building are recognized techniques to address the energy and environmental crises. In this regard, the Trombe Wall has also attracted attention for its potential ability to address the energy and environmental crises. Trombe Wall is regarded as a sustainable architectural technology for insulation. This article reviews the classification and configuration of Trombe Wall and the most relevant content of Trombe Wall research carried out in various countries over the past few decades. This review discusses the characteristics of the main subspecies of the Trombe Wall. In terms of content, according to the research methods of different types of Trombe walls, they can be divided into two categories: theoretical simulation research and experimental research. The advantages of this sustainable architectural technology have been highlighted, and future research questions have been identified.
\end{abstract}

\section{Introduction}

Massive energy consumption has caused global warming and threatened the survival and development of people. It is now widely accepted that one of the promising methods is to use solar energy to provide auxiliary clean energy. The substitution of solar energy for traditional energy will not only improve the thermal comfort indoors, but also reduce energy consumptions and emissions of $\mathrm{CO}_{2}$ as well as protect the ecology and cut down the economic costs of heating [1]. The importance of passive solar heating technology becomes even more evident when considering the use of buildings and nonfossil fuels. Among the numerous solar technology studies, the Trombe Wall is the most common passive solar heating system $[2,3]$.

Since French scholar Felix Trombe put forward the Trombe wall technology in the 1860s, the passive solar heating technology based on the Trombe wall principle has been widely studied and applied by scholars [4-7]. The traditional Trombe wall has the advantages of simple configuration, high efficiency, zero cost of operation, etc. The traditional Trombe wall can use clean energy to improve indoor air quality, improve indoor thermal comfort, and reduce energy consumption for heating in winter and cooling in summer. However, the traditional Trombe wall has several shortcomings: 1 . Low thermal resistance; 2. Reverse thermosiphon phenomenon; 3. Heat transfer is always uncertain; 4. Low aesthetic value. Therefore, with the improvement of the requirements of structural transformation, material selection, design optimization and engineering practice, the traditional Trombe wall system with a single function has been unable to meet the performance requirements of buildings, and many types of Trombe wall systems have been proposed.

\section{Classification and design description for various types of Trombe walls.}

According to different configurations, the proposed Trombe wall can be divided into 9 different types: (1) a modified Trombe wall; (2) a zigzag Trombe wall; (3) a solar water wall; (4) a Trombe wall with venetian blind (VBTW); (5) a solar trans-wall; (6) a Trombe wall with phase-change material (PCM); (7) a composite Trombe wall (Trombe-Michel wall); (8) a fluidized Trombe wall; (9) a photovoltaic Trombe wall (PVTW) [8]. According to the main function of Trombe wall, the nine configured walls can be divided into two types: heating type and cooling type [9].

\subsection{A modified Trombe wall}

The classic Trombe wall system is mainly composed of glass plates, air layer and the heat storage wall from the outside to the inside. To improve the thermal efficiency of the classic Trombe wall, various design schemes of the wall structure have been developed. Solutions such as automatic vents, fans, ventilating louvers, and protection and thermal insulation coatings have been developed, all of which are called improved Trombe walls $[11,12]$.

\subsection{A zigzag Trombe wall}

In order to reduce excessive heat gain and glare on sunny days, maximize the use of solar radiation and provide the room with the amount of daylight needed, the classic Trombe wall is modified into different shapes, thus forming another type of Trombe wall, the zigzag Trombe wall. The window openings of the zigzag Trombe wall

\footnotetext{
* Corresponding author: maqingsong@qut.edu.cn
} 
are all oriented toward the southeast and the thermal wall toward the southwest, both of which inclined inward to form a V-shaped wall [10].

\subsection{A solar water wall}

Replace the masonry heat storage wall of the classic Trombe wall system with a wall-shaped water container, which is another type of Trombe wall-solar water wall, which works on the same principle as the classic Trombe wall [11]. The solar water wall can be used for both cooling and heating, which is a major feature of this one.

\subsection{A Trombe wall with venetian blind}

In order to reduce convective heat loss and improve heating performance, VB-Trombe Wall has venetian blind installed between the glass plate and the thick wall of the traditional Trombe Wall [12-14]. This construction of the Trombe wall is an improvement on the shading Trombe wall [15]. It is an advanced Trombe wall.

\subsection{A solar trans-wall}

The solar trans-wall is built on a metal frame that houses a water container made up of a glass wall and a translucent absorption panel located between the walls. The translucent panel absorbs the solar energy and transmits the remaining energy into the interior. There are many types of solar trans-wall [16], and research and analysis reveal two major shortcomings: the complexity of the design and the high cost of the equipment.

\subsection{A Trombe wall with phase-change material}

Phase change materials (PCM) such as eutectic salts or salt hydrates of the same volume can store more energy than ordinary building materials. By replacing the masonry heat storage wall of the classic Trombe wall system with a phase change material, the efficiency is improved. It constitutes this new type of Trombe wall [17]. Since different phase change materials have different effects on the performance of Trombe walls, exploring the use of different phase change materials in Trombe walls is valuable for reducing building energy consumption $[18,19]$.

\subsection{A composite Trombe wall}

Composite Trombe wall, also known as Trombe-Michel wall, is another type of Trombe wall, which is mainly composed of transparent material panels, air layer, heat storage wall, air layer and insulation wall from outside to inside [20]. The composite Trombe wall adds an additional air layer to the traditional Trombe wall, which increases the thermal resistance of the system (Fig. 1). Through ventilation control, the inverse thermosiphon phenomenon of the traditional Trombe wall can also be improved, and the composite Trombe wall has a higher energy-saving effect than the traditional Trombe wall $[21,22]$.

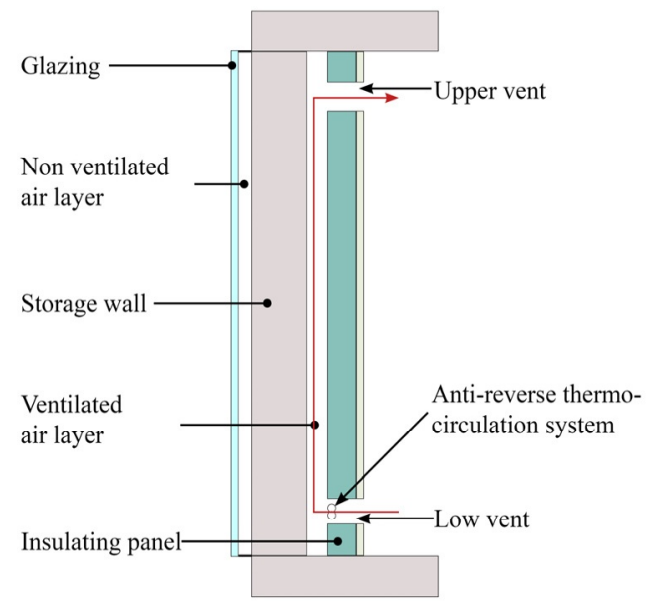

Fig. 1. A composite Trombe wall.

\subsection{A fluidized Trombe wall}

Another type of Trombe wall is the fluidized Trombe wall, which is designed on the basis of the classic Trombe wall, that is, the gap between the glass and the heat storage wall is filled with high-absorption and lowdensity fluid. The operating principle is based on the fluidization: cold indoor air is heated through a fluid and sent back to the room.

\subsection{A photovoltaic Trombe wall}

Photovoltaic Trombe wall (PVTW) combines the glass plate, air layer or heat storage wall of classic Trombe wall with photovoltaic panels, realizing the integration of light, heat and electricity. It is the most common Trombe integrated wall. Meanwhile, the dark blue solar photovoltaic panels add beauty to the building. It is suitable for areas with abundant solar radiation resources. Of course, due to the different working principles of the Trombe walls and photovoltaic panels, the photothermal and photovoltaic efficiency of PVTW are worth exploring [23, 24].

\section{Research description of various types of structural solutions for Trombe wall}

At present, scholars mainly study the performance of different Trombe walls optimized from "site" parameters (climate, orientation and solar radiation), "building" parameters (windows and building materials) and "Trombe wall" parameters (structure, equipment and material properties). Generally, these studies can be classified through numerical simulation and experimental research.

\subsection{In terms of numerical simulation or theoretical research}

Bushov studied the heat loss of buildings in cold climates, and the results showed that the feasibility of 
using zigzag Trombe wall was zero [25]. Liu and Feng simulated the heating and cooling loads of buildings with solar water wall and found that they reduced the number of hours of discomfort in the room by nearly a third and the annual heat load by $25 \%$ [26]. Leang et al. used Dymola/Modelica software to investigate the performance of the M PCM (mortar phase change material) composite Trombe walls. They compared the M_PCM composite Trombe wall with the concrete composite Trombe wall. The results show that the M_PCM composite Trombe wall has greater heat recovery capability [27].

Shen et al. investigated the thermal performance of two passive solar systems, a traditional Trombe wall and a composite Trombe wall. The results show that the developed model is very accurate and the composite Trombe wall has better energy performance than the traditional Trombe wall in cold and cloudy weather [28, 29]. Bellos et al. proposed a new Trombe wall system with additional Windows on passive walls and compared it with a traditional Trombe wall system and traditional insulated wall system by simulation. The results show that the proposed new system can not only create a warmer interior environment, but also solve some aesthetic problems of the traditional Trombe wall [30]. Chen and Liu used the unstable numerical simulation method to study the heat transfer and airflow of the solar collector with porous absorption composite wall [31]. Taffesse et al. developed a mathematical model of SPVT-TW (semi-transparent photovoltaic Trombe wall) using MATLAB R2013a software, and optimized the indoor air temperature, thermal load level and thermal heating reduction coefficient. The calculation results showed that the optimal value of photovoltaic Trombe wall thickness of thermal load levelling was $0.4 \mathrm{~m}$ [32].

\subsection{In terms of experimental research}

Rabani et al. conducted an experimental analysis of the thermal performance of the modified Trombe wall, which could obtain too radiant heat from the south, west and east directions. The results show that the thermal performance of the modified Trombe wall is better than that of the traditional Trombe wall. This type of Trombe wall can make the maximum temperature of the heat storage material $10^{\circ} \mathrm{C}$ higher than the traditional Trombe wall, and the cost is lower [33]. Adams et al. conducted an experimental analysis on the performance of solar water wall with three different thicknesses of water storage walls (3 inches, 6 inches and 9 inches). The results showed that the 9-inch and 6-inch walls performed better than the 3-inch walls [34].

Liu et al. studied the application of solar hybrid double-layer walls for natural ventilation and air heating in buildings. The effects of the ventilation passage width and solar radiation intensity on the outlet temperature distribution and induced air flow of the mixed wall were studied. The results show that there exists a minimum temperature position in the air passage, and the position varies with the width of the air gap [35]. Zalewski et al. conducted an experimental study on a small PCM-
Trombe wall containing inorganic hydrated salts, and the results showed that the hydrate salts-containing brick could shorten the release time delay of solar energy benefits by almost 2.5 times, and the time delay of the hydrate salts-containing brick was $2 \mathrm{H} 40$ [36]. Ji et al. studied the practical application effect of some PVTrombe wall improvement measures, and the experimental results showed that the electric energy generated by this Trombe wall was better than the thermal energy quality [37-39].

\section{Conclusions}

Trombe wall is receiving considerable attention and proven to be highly useful and significant in current environment protection and energy conservation. In the present study, a detailed literature survey of the important contributions of the Trombe wall related studies carried out during the last 15 years has been performed. This research will provide an important reference for future new buildings and renovations of existing building, and has important practical and farreaching strategic significance for achieving carbon neutrality in buildings.

\section{Acknowledgments}

This research is supported by grants from the Natural Science Foundation of Shandong Province (No. ZR201910280141).

\section{References}

1. Luo, G., et al., Preliminary Assessment on the Potential Use of Solar Energy in House Heating: A Case Study of an Elementary Classroom with Attached Sunspace in Lintan County, Gansu Province, in 2011 International Conference on Computer Distributed Control and Intelligent Environmental Monitoring. 2011.p. 1637-1641.

2. Hami, K., B. Draoui, and O. Hami, The thermal performances of a solar wall. Energy, 2012. 39(1): p. 11-16.

3. Duan, S.P., C.J. Jing, and Z.Q. Zhao, Energy and exergy analysis of different Trombe walls. Energy and Buildings, 2016. 126: p. 517-523.

4. Janis, B., Positive Development:From Vicious Circles to Virtuous Cycles through Built Environment Design. 2012: Taylor and Francis. 2012.

5. Agrawal, B. and G.N. Tiwari, Building Integrated Photovoltaic Thermal Systems:For Sustainable Developments. 2010: RSC. 2010.

6. Sadineni, S.B., S. Madala, and R.F. Boehm, Passive building energy savings: A review of building envelope components. Renewable and Sustainable Energy Reviews, 2011. 15(8): p. 3617-3631.

7. Zhang, L., et al., Numerical simulation and sensitivity analysis on an improved Trombe wall. 
Sustainable Energy Technologies and Assessments, 2021. 43: p. 100941.

8. Sergei, K., C. Shen, and Y. Jiang, A review of the current work potential of a trombe wall. Renewable \& Sustainable Energy Reviews, 2020. 130.

9. $\mathrm{Hu}, \mathrm{Z}$., et al., A review on the application of Trombe wall system in buildings. Renewable and Sustainable Energy Reviews, 2017. 70: p. 976-987.

10. Saadatian O, et al., Solar walls: the neglected components of passive designs. . Advanced in Environment, Biotechnology and Biomedicine 2012:120-6., 2012.

11. Tyagi, V.V. and D. Buddhi, PCM thermal storage in buildings: A state of art. Renewable and Sustainable Energy Reviews, 2007. 11(6): p. 1146-1166.

12. He, W., et al., Thermal and hydraulic analysis on a novel Trombe wall with venetian blind structure. Energy and Buildings, 2016. 123: p. 50-58.

13. He, W., et al., The thermal behavior of Trombe wall system with venetian blind: An experimental and numerical study. Energy and Buildings, 2015. 104: p. 395-404.

14. Hong, X., et al., Three-dimensional simulation on the thermal performance of a novel Trombe wall with venetian blind structure. Energy and Buildings, 2015. 89: p. 32-38.

15. Chen, B., et al., Shading effects on the winter thermal performance of the Trombe wall air gap: An experimental study in Dalian. Renewable Energy, 2006. 31(12): p. 1961-1971.

16. Melero, S., et al., Passive evaporative cooling by porous ceramic elements integrated in a Trombe wall. . Architecture \& sustainable development 2011. 2: p. 267.

17. Sharma, A., et al., Review on thermal energy storage with phase change materials and applications. Renewable and Sustainable Energy Reviews, 2009. 13(2): p. 318-345.

18. Khalifa, A.J.N. and E.F. Abbas, A comparative performance study of some thermal storage materials used for solar space heating. Energy and Buildings, 2009. 41(4): p. 407-415.

19. Fiorito, F., Trombe Walls for Lightweight Buildings in Temperate and Hot Climates. Exploring the Use of Phase-change Materials for Performances Improvement. Energy Procedia, 2012. 30: p. 11101119.

20. Marinosci, C., et al., Empirical validation and modelling of a naturally ventilated rainscreen façade building. Energy and Buildings, 2011. 43(4): p. 853863.

21. Ma, Q.S., et al., Study of a Double-Layer Trombe Wall Assisted by a Temperature-Controlled DC Fan for Heating Seasons. Sustainability, 2017. 9(12).

22. Ma, Q.S., et al., Optimizing energy performance of a ventilated composite Trombe wall in an office building. Renewable Energy, 2019. 134: p. 12851294.
23. Bajc, T., M.N. Todorović, and J. Svorcan, CFD analyses for passive house with Trombe wall and impact to energy demand. Energy and Buildings, 2015. 98: p. 39-44.

24. Ghazali, A., et al., Photovoltaic Façade in Malaysia: The Development and Current Issues. Research Journal of Applied Sciences, Engineering and Technology, 2016. 13(8).

25. A.Bushov, Space-planning solution and its impact on the energy efficiency and microclimate of the Academia building. . Architect Constr 2010:251-2., 2010.

26. Liu, Y.W. and W. Feng, Integrating Passive Cooling and Solar Techniques into the Existing Building in South China. Advanced Materials Research, 2012. 368-373: p. 3717-3720.

27. Leang, E., et al., Numerical study of a composite Trombe solar wall integrating microencapsulated PCM. Energy Procedia, 2017. 122: p. 1009-1014.

28. Shen, J., et al., Numerical study on thermal behavior of classical or composite Trombe solar walls. Energy and Buildings, 2007. 39(8): p. 962-974.

29. Shen, J., et al., Numerical study of classical and composite solar walls by TRNSYS. Journal of Thermal Science, 2007. 16(1): p. 46-55.

30. Bellos, E., et al., An innovative Trombe wall as a passive heating system for a building in Athens-A comparison with the conventional Trombe wall and the insulated wall. Energy and Buildings, 2016. 133: p. 754-769.

31. Chen, W. and W. Liu, Numerical analysis of heat transfer in a composite wall solar-collector system with a porous absorber. Applied Energy, 2004. 78(2): p. 137-149.

32. Taffesse, F., et al., Periodic modeling of semitransparent photovoltaic thermal-trombe wall (SPVT-TW). Solar Energy, 2016. 135: p. 265-273.

33. Rabani, M., et al., Experimental study of the heating performance of a Trombe wall with a new design. Solar Energy, 2015. 118: p. 359-374.

34. S, A., et al., Not a dry subject: optimizing water Trombe wall. Proceedings of the Solar Energy Society Annual Conference 2010, 2010.

35. Liu, B., et al., Experimental study of the chimney effect in a solar hybrid double wall. Solar Energy, 2015. 115: p. 1-9.

36. Zalewski, L., et al., Experimental study of smallscale solar wall integrating phase change material. Solar Energy, 2012. 86(1): p. 208-219.

37. Jie, J., et al., PV-Trombe Wall Design for Buildings in Composite Climates. Journal of Solar Energy Engineering, 2006. 129(4): p. 431-437.

38. Jie, J., et al., Study of PV-Trombe wall installed in a fenestrated room with heat storage. Applied Thermal Engineering, 2007. 27(8-9): p. 1507-1515. 
39. Jie, J., et al., Study of PV-Trombe wall assisted with DC fan. Building and Environment, 2007. 42(10): p. 3529-3539. 